Article

\title{
Transient Mechanical Response of Lung Airway Tissue during Mechanical Ventilation
}

\author{
Israr Bin Muhammad Ibrahim ${ }^{1}$, Parya Aghasafari ${ }^{1}$ and Ramana M. Pidaparti ${ }^{2, *}$ \\ Received: 30 September 2015; Accepted: 24 December 2015; Published: 5 January 2016 \\ Academic Editor: Aldo Boccaccini \\ 1 Graduate Student, College of Engineering, University of Georgia, 597 DW Brooks Drive, Athens, GA 30602, \\ USA; israr@uga.edu (I.B.M.I.); parya.aghasafari@uga.edu (P.A.) \\ 2 College of Engineering, University of Georgia, 132A Paul D. Coverdell Center, Athens, GA 30602, USA \\ * Correspondence: rmparti@uga.edu; Tel.: +1-706-542-4057
}

\begin{abstract}
Patients with acute lung injury, airway and other pulmonary diseases often require Mechanical Ventilation (MV). Knowledge of the stress/strain environment in lung airway tissues is very important in order to avoid lung injuries for patients undergoing MV. Airway tissue strains responsible for stressing the lung's fiber network and rupturing the lung due to compliant airways are very difficult to measure experimentally. Multi-level modeling is adopted to investigate the transient mechanical response of the tissue under MV. First, airflow through a lung airway bifurcation (Generation 4-6) is modeled using Computational Fluid Dynamics (CFD) to obtain air pressure during 2 seconds of MV breathing. Next, the transient air pressure was used in structural analysis to obtain mechanical strain experienced by the airway tissue wall. Structural analysis showed that airway tissue from Generation 5 in one bifurcation can stretch eight times that of airway tissue of the same generation number but with different bifurcation. The results suggest sensitivity of load to geometrical features. Furthermore, the results of strain levels obtained from the tissue analysis are very important because these strains at the cellular-level can create inflammatory responses, thus damaging the airway tissues.
\end{abstract}

Keywords: mechanical strains; lung airway; mechanical ventilation; finite element analysis

\section{Introduction}

Patients with respiratory problems whose lungs are compromised are treated with Mechanical Ventilation (MV) to assist them with breathing. MV can cause injury to airway lung tissue resulting from air pressure, and may eventually also cause damage to the lungs [1,2]. In general, the incidence of respiratory failures resulting from ventilator-associated lung injury (VALI) [3-5] is increasing due to the fact that there are still unanswered questions with regards to the transmission of mechanical forces into lung tissues resulting from MV. Mechanical aspects of VILI have been reported in past works, such as [3-5]. From these studies, ventilator management practices have been developed, such as maintaining positive end-expiration pressure. Despite this development, MV-induced damage may still lead to systemic organ failure called biotrauma [6]. Mechanical strain caused by ventilators has been shown to cause cell signaling, leading to inflammation [7]. It has also been shown that the inflammation depends on the mode of MV [8,9].

Several studies have been conducted to model air pressure on lung airway wall with diseases, such as tumors [10,11] and chronic obstructive pulmonary disease [12,13]. Fluid-solid interaction modeling using the Finite Element Method (FEM) has been employed by Koombua, et al. [14] to study airflow characteristics and stress distribution on airway walls. The results in [14] were used in [15] and [16] to analyze stress and strain distribution occurring on a more detailed model of tissue. 
However, the previous studies did not employ a full breathing cycle. The complex dynamics of lung tissue environment are still being investigated, and, although significant research has been done, there are still unanswered questions with regards to the transmission of mechanical forces into lung tissues resulting from MV. Even though there have been many studies investigating the effects of long term ventilation with respect to lungs, the connection between the global deformation of the whole lung and the strains reaching the lung tissue has not been studied. Capturing real-time progression of airway tissue stretch during breathing is still difficult to assess experimentally. Currently, there is a lack of data on real-time stretch progression of airway tissue during MV.

In this study, a scheme for studying real-time progression of airway tissue stretch is proposed. The scheme only incorporates fundamental dynamics of airway tissue structure to save on the computational cost of simulation. The scheme consists of two steps. First, airflow through a lung airway bifurcation (Generation 4-6) is modeled using Computational Fluid Dynamics (CFD) to obtain air pressure during MV breathing with a flow rate of $35 \mathrm{~L} / \mathrm{min}$, as a follow up on results from a previous study [17]. Next, the transient air pressure was used in structural analysis to obtain mechanical strain experienced by the airway tissue wall. Several simulations were carried out to investigate the stress/strain environment within the airway lung tissue, and the results are presented and discussed.

\section{Materials and Methods}

\subsection{Airway Tissue Model}

Human lung consists of bifurcating airways that begin at the trachea. The trachea is designated as Generation 0 . The generation numbers are then counted from bifurcating airways that grow after the trachea. The total number of generations in the human lung is 23 . In this study, airway bifurcation of Generation 4-6 is considered.

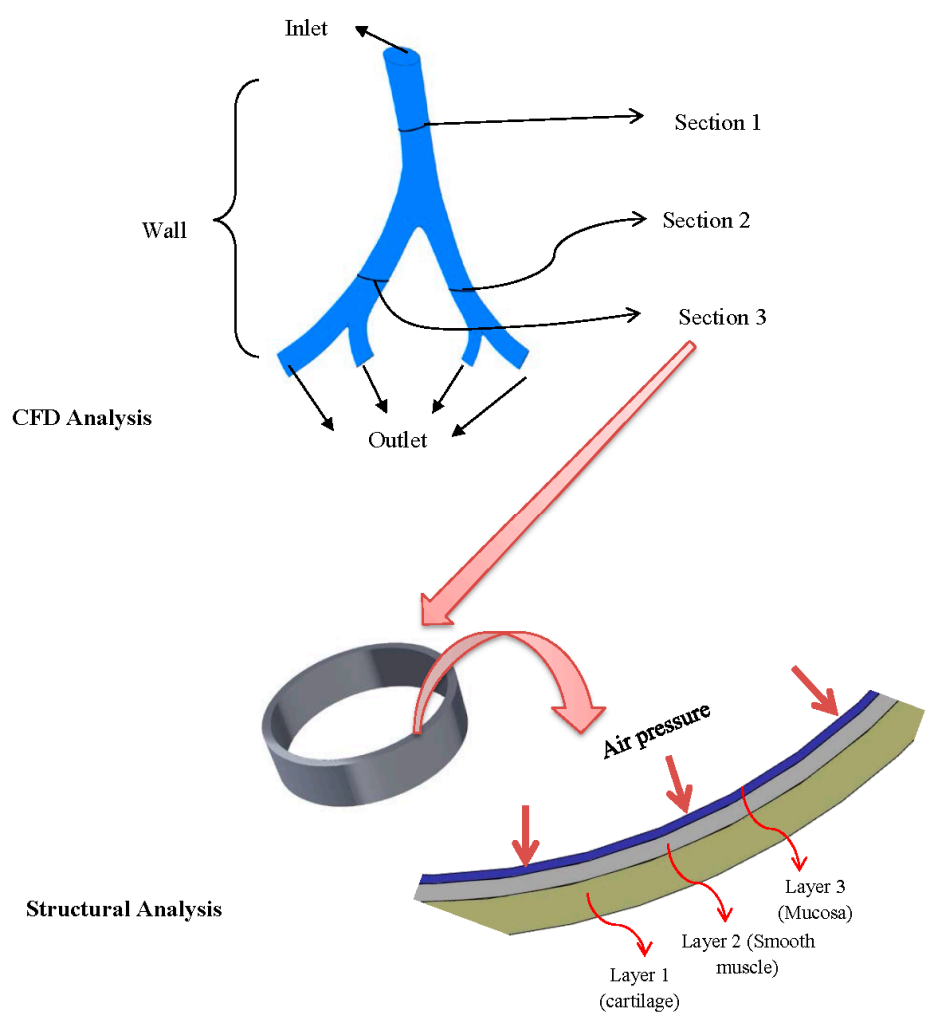

Figure 1. Multi-level analysis adopted for transient mechanical response of airway lung tissue. Top: model and boundary condition used for fluid flow analysis. Bottom: model for mechanical analysis. 
A three-dimensional model of lung bifurcation Generation 4-6 was built based on approximation of a realistic human lung model. For the mechanical response analysis, the model was based on airway representation as discussed by Kamm [18]. The upper lung airway (Generation 1-8) is composed of three major layers based on the composition of each layer: mucosa, sub-mucosa and the area outside of the submucosa [19]. The submucosa includes the smooth muscle tissue. The area outside the submucosa consists of cartilage-fibrous layer and adventitia. In this study, a slice of airway model is considered for simplicity. The airway is assumed to stretch in radial and axial directions. The structure of the airway was simplified into a basic fundamental structure to capture the main dynamics of the airway. Figure 1 show the lung bifurcation along with the tissue layer model used in this study. Each layer is named as shown in Figure 1 for later discussion.

\subsection{Computational Models and Boundary Conditions}

In this study, two separate models were investigated using multi-level modeling. First, airflow through a lung airway bifurcation (Generation 4-6) is modeled using Computational Fluid Dynamics (CFD) to obtain air pressure (airflow model). Next, the transient air pressure was used in structural analysis to obtain mechanical strain experienced by the airway tissue wall (airway deformation model).

\subsubsection{Airflow Model}

The momentum of airflow through the lung bifurcation was assumed to follow the Navier-Stokes equations:

Conservation of mass:

$$
\frac{\partial \rho}{\partial t}+\nabla \cdot(\rho \mathbf{v})=0
$$

Conservation of momentum

$$
\rho\left(\frac{\partial \mathbf{v}}{\partial t}+\mathbf{v} \cdot \nabla \mathbf{v}\right)=-\nabla p+\nabla \cdot\left(\mu\left(\nabla \mathbf{v}+(\nabla \mathbf{v})^{T}\right)\right)
$$

where $\rho$ is fluid density, $\mathbf{v}$ is velocity and $p$ is pressure. The viscous force term in Equation (2) is in the form of incompressible viscous flow, which is the assumption of flow in airway Generation 4-6. The domain for the equations was the solid model as shown in Figure 1. Boundary conditions for Equations (1) and (2) were as follows: a velocity boundary conditions was imposed at the inlet "top" part of airway as in Figure 1) and a pressure outlet boundary conditions at the four outlets ("bottom" part of airway as in Figure 1) assuming flow exits the bifurcation unobstructed. No-slip boundary conditions are imposed at the walls. For the pressure and velocity conditions occurring in the lung geometry, the flow is assumed to be incompressible. A rectangular MV flow rate waveform was considered in this study. A model was developed to approach the rectangular MV waveform $[17,20]$. The wave was modeled as a function of airway area and generation number. The equations are as follows:

$$
\begin{gathered}
v(t)=\frac{Q}{A 2^{N}-1} \\
v(t)=T V \cdot \frac{e^{-\left(t-t_{i}\right) / \tau}}{A 2^{N}-1}
\end{gathered}
$$

where $t_{i}$ is total inspiration time, $N$ is generation number, $A$ is cross section of airway under consideration (in this case, the airway Generation 4 model), $\mathrm{Q}$ is averaged flow rate, $T V$ is tidal volume of lung bifurcation, and $\tau$ is ratio of tidal volume and flow rate. The flow rate is equal to the ratio of tidal volume and inspiration time. Equation (3) was used as an approach for studying inspiration airflow, and Equation (4) was used to assess expiration airflow during MV breathing. The analysis was carried out for MV breathing with a flow rate of $35 \mathrm{~L} / \mathrm{min}$, following [17]. Hence, to maintain the flow rate, the tidal volume was chosen to be $14 \mathrm{~mL}$, and inspiration and expiration times were chosen to be $0.4 \mathrm{~s}$ and $1.6 \mathrm{~s}$, respectively. 
Figure 1 shows three parts of the airway wall that are designated as Sections $1-3$. Section 1 is the biggest airway in the model, followed by Sections 2 and 3. Pressures along these sections were obtained for a subsequent airway wall mechanical response analysis.

\subsubsection{Airway Deformation}

The lung airway tissue was assumed to be an elastic material. The stress developed in the tissue by pressure applied on it was modeled using the Cauchy momentum relationship:

$$
\frac{\partial \sigma_{i j}}{\partial x_{j}}=\rho \frac{\partial^{2} u_{i}}{\partial t^{2}}
$$

The constitutive equation is a linear elastic material as follows:

$$
\sigma_{i j}=E \epsilon_{i j}
$$

where $\sigma$ is stress tensor, $\epsilon$ is strain, $u$ is displacement, $E$ is elastic moduli, $t$ is time and $\rho$ is mass density. In this study, a cylindrical coordinate was used to define direction. Hence, the subscript refers to radial (r), rotational $(\theta)$ and (in three-dimensional case) axial (z) directions, respectively. The domain of Equation (5) is a slice of lung airway as shown in Figure 1. Radial contraction by smooth muscle is the dominant type of contraction when the lung airway inhales air. In this study, we are interested in the fundamental dynamics of the airway. Hence, the thickness of the model was determined to be one-third of its diameter to ensure the radial response is dominant over axial ones.

The diameters were chosen to approach three sections in the CFD analysis. These diameters are: $2.5 \mathrm{~mm}$ for Section 1, $1.86 \mathrm{~mm}$ for Section 2 and $1.45 \mathrm{~mm}$ for Section 3. The tissue model consists of three layers as shown in Figure 1. The thickness of layers for each section is shown in Table 1. The layers were modeled as an isotropic material. The Young's moduli are $75 \mathrm{KPa}$ for smooth muscle and cartilage layer, and $115 \mathrm{KPa}$ for mucosa layer. Poisson's ratio for all three layers is 0.45 . The density is assumed to be $1365.6 \mathrm{~kg} / \mathrm{m}^{3}$, after the work of Koombua and Pidaparti [14]. Isotropic material relation was used in this study since the focus of our study was to analyze the basic dynamics (axial and radial structural response) of the tissue. A recent study by Weed et al. [21] also shows evidence of isotropy at least in lung parenchyma. Furthermore, Xia et al. [22] described in their work that an anisotropic effect appears when tissue strains reached $20 \%$. In this study, small strain assumption was used for the tissue analysis. To compare the linear isotropic material relationship with non-linear ones, two non-linear material relationships were applied. The Neo-Hookean material relationship was used with parameters as outlined in [15]; $C_{10}=0.56 \mathrm{MPa}, \mu=1.12 \mathrm{MPa}$ and incompressibility parameter, $d=2.14 \times 10^{-8}$. Ogden material model was also used, based on measurement by Zeng, et al. [23]. The parameters were as follows; $\mu_{1}=177.93 \mathrm{~Pa}, A_{1}=5.0424$, incompressibility parameter, $D_{1}=0$.

Table 1. Material model for each layer of the airway tissue.

\begin{tabular}{ccccc}
\hline \multirow{2}{*}{ Layer Name } & \multirow{2}{*}{ Layer Number } & \multicolumn{3}{c}{ Thickness at Each Section } \\
\cline { 3 - 5 } & & Section 1 & Section 2 & Section 3 \\
\hline Mucosa & Layer 1 & $66.56 \mu \mathrm{m}$ & $49.59 \mu \mathrm{m}$ & $38.61 \mu \mathrm{m}$ \\
Smooth Muscle & Layer 2 & $31.95 \mu \mathrm{m}$ & $22.17 \mu \mathrm{m}$ & $18.53 \mu \mathrm{m}$ \\
Cartilage & Layer 3 & $15.29 \mu \mathrm{m}$ & $11.37 \mu \mathrm{m}$ & $8.86 \mu \mathrm{m}$ \\
\hline
\end{tabular}

The boundary conditions were as follows: the model was subjected to transient pressures on the inner surface of the airway model. The transient pressures are obtained from airflow simulation described in the previous section. The displacement in the circular direction was constrained, following the assumption described above. The slice of tissue is supposed to be a part of the larger airway. It was assumed that one side of the slice gave better support than another. Hence, one side's face was constrained in the axial direction. 


\subsubsection{Numerical Solution to the Models}

The model equations were all solved by Finite Element Analysis through ANSYS v.14 software. Both models were discretized using ANSYS meshing module. Fluent component of ANSYS was used to solve Equations (1) and (2) with boundary conditions mentioned earlier. A User-Defined Function (UDF) code was built for generating velocity inlet boundary conditions as expressed in Equations (3) and (4). The fluid domain was discretized with 428,834 tetrahedral elements. ANSYS Mechanical was used to solve Equation (7). The tissue domain was discretized with 277,440 tetrahedral elements.

\section{Results and Discussion}

\subsection{Airflow Simulation}

By applying CFD analysis to lung bifurcation 4-6 using the approach described above, velocity field and air pressure inside the lung airway were obtained. Figure 2 shows contour of velocity in the immediate bifurcation after the inlet of Generation 5 airway. It can be seen from Figure 2 that the velocity patterns during inspiration and expiration are different. The velocity patterns presented in Figure 2 followed a horseshoe pattern, as previously shown in studies by Sul et al. [24] and Isabey and Chang [25]. This finding provides preliminary validation that the present analysis is reasonable for estimating the fluid dynamics characteristics.

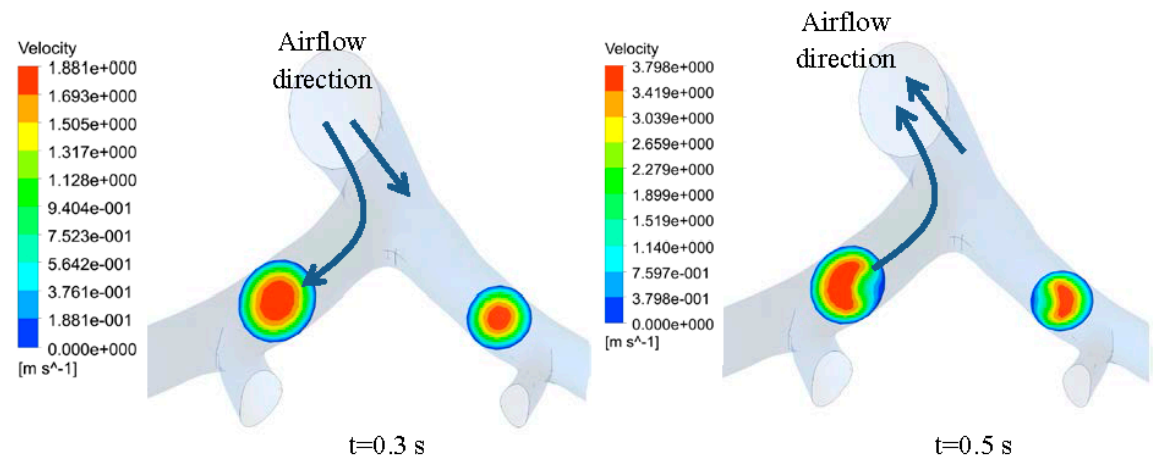

Figure 2. Velocity contour on bifurcation of Generation 5 lung airway, showing tendency to form horseshoe pattern.

The average pressure on three different regions of the bifurcations (Sections 1-3) is presented in Figure 3 in order to see how the MV air pressure affects the tissues. It can be seen from Figure 3 that the pressure variation with time follows the MV velocity waveform. Also, the pressure is higher in Section 1 in comparison to other bifurcation locations (Sections 2 and 3).
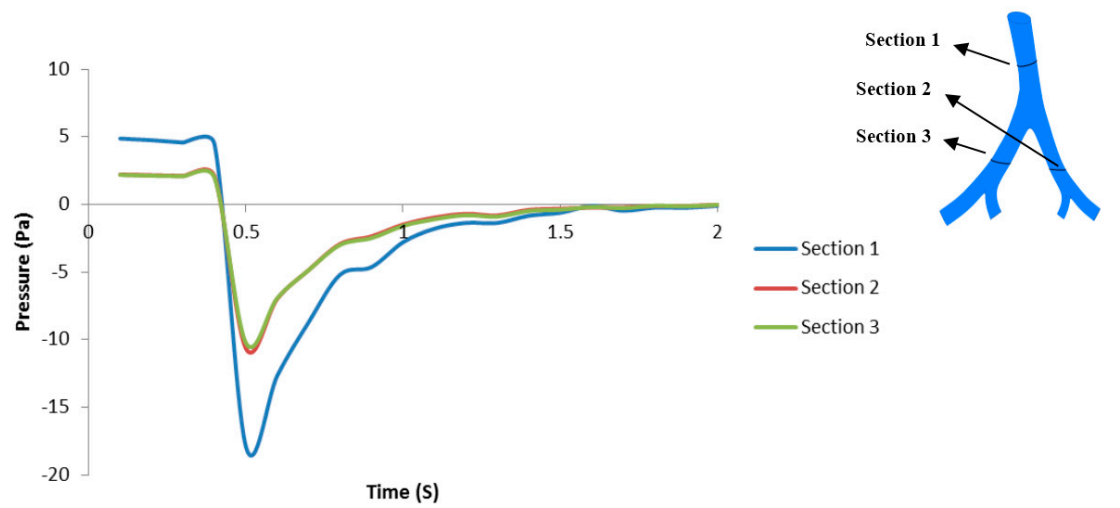

Figure 3. Average transient pressure for MV breathing in Sections 1-3 obtained from airflow simulation. 
The pressure along the airway at several locations at various times during inspiration and expiration is shown in Figures 4 and 5. At the bifurcation junction, the pressure is concentrated in the center of the junction. In this area, the pressure on the left side of the junction is higher in value than on the right. The variations of pressure in all these location are shown to be less than $3 \mathrm{~Pa}$. These results suggest that the MV air pressure is non-linear along the radial path of the airway. There are concentrations of pressure on the three junctions during inspiration.

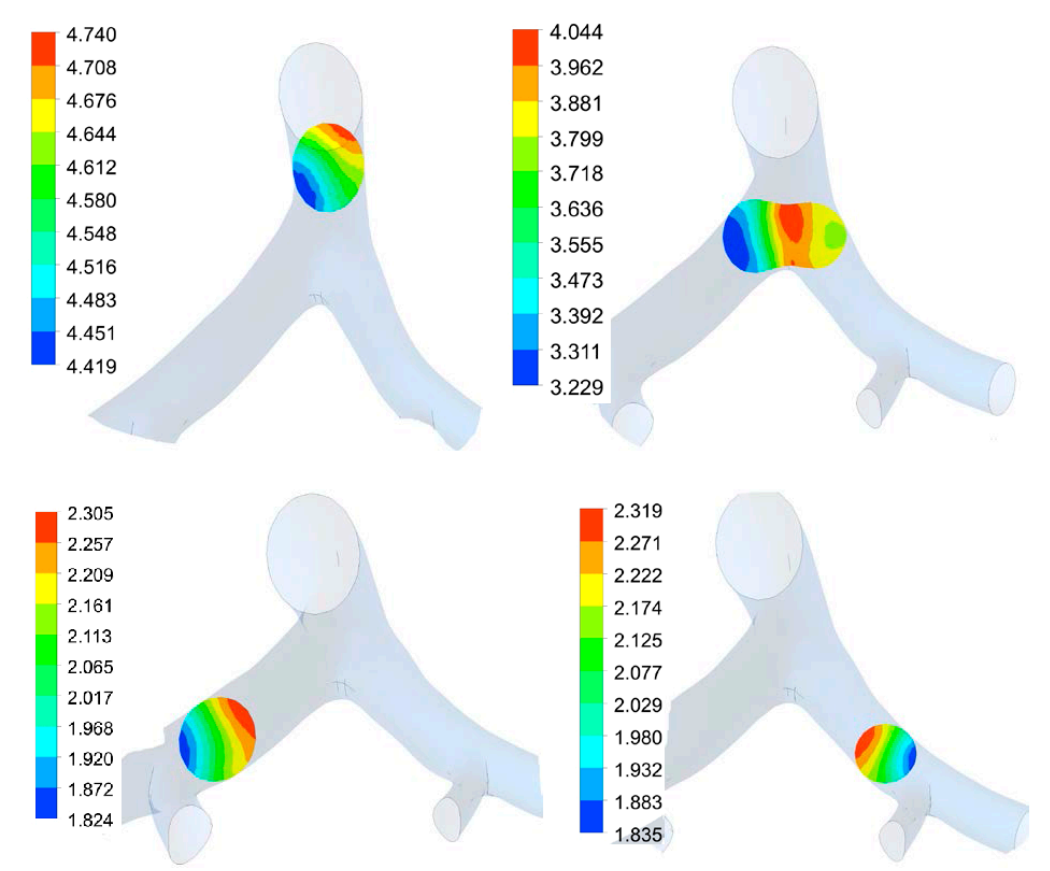

Figure 4. Pressure distribution in lung airway at several locations along airway at $t=0.3 \mathrm{~s}$ (inspiration) on four section, including junction. Color legend shows pressure value range in Pascal.

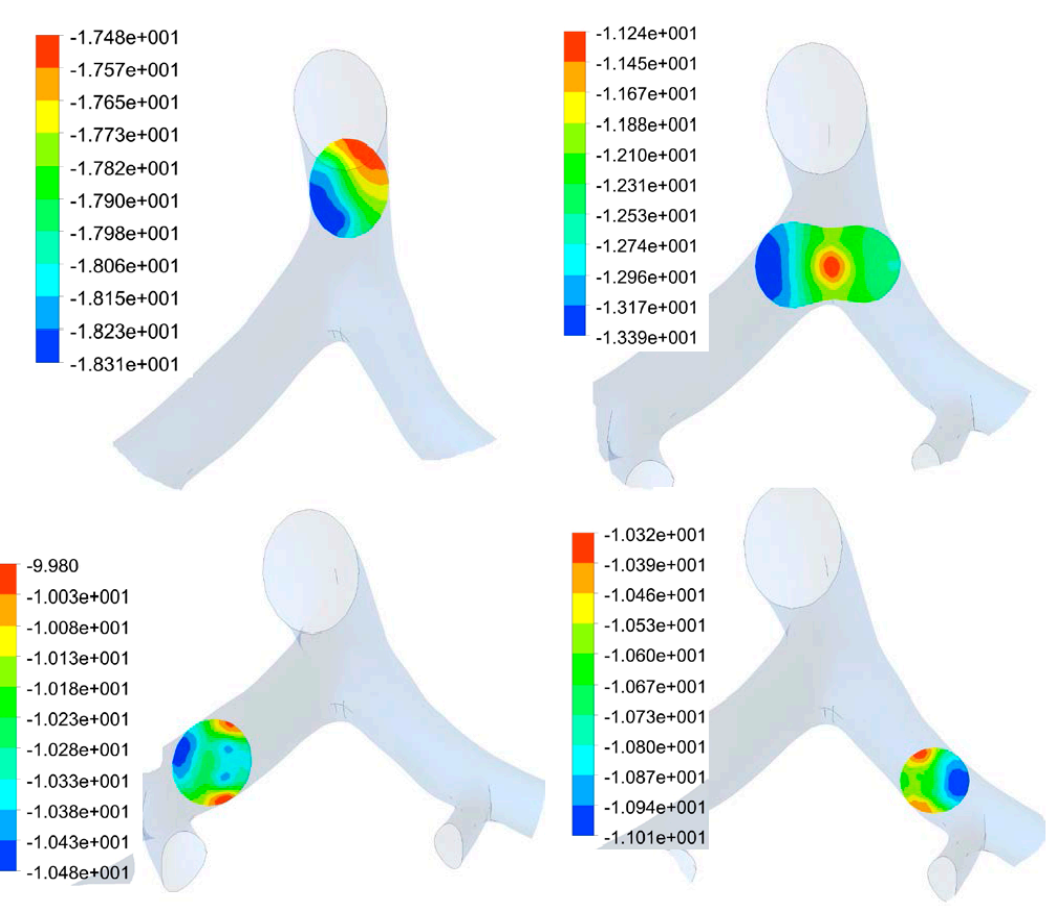

Figure 5. Pressure distribution in lung airway at several locations along airway at $t=0.5 \mathrm{~s}$ (peak expiration) on four section, including junction. Color legend shows pressure value range in Pascal. 


\subsection{Transient Mechanical Response}

\subsubsection{Mesh Convergence Study}

Mesh convergence test was carried out before determining that the number of elements as mentioned in Section 2.2.2 was sufficient for this study. The tissue domain was discretized three times with an increasing number of elements as described in Figure 6. The Von Mises strains at two time values were chosen for comparison. The two time values will also be used in later sections. The inspiration time value of $0.3 \mathrm{~s}$, which is close to start of expiration, was chosen. The second time value chosen was $t=0.5 \mathrm{~s}$, which is the amplitude of the MV wave.

Figure 6 shows maximum and minimum Von Mises strain at these time values. It can be seen clearly from Figure 6 that the Von Mises strain has reached convergence at first discretization with 277,440 elements. As shown in Tables 2 and 3 a solution obtained with 784,992 elements was named Case 3. Data presented in Tables 2 and 3 also show that the differences between solution (Von Mises strain) of Case 3 and two other cases are negligible. Thus, discretization with 277,440 elements was chosen for this study.

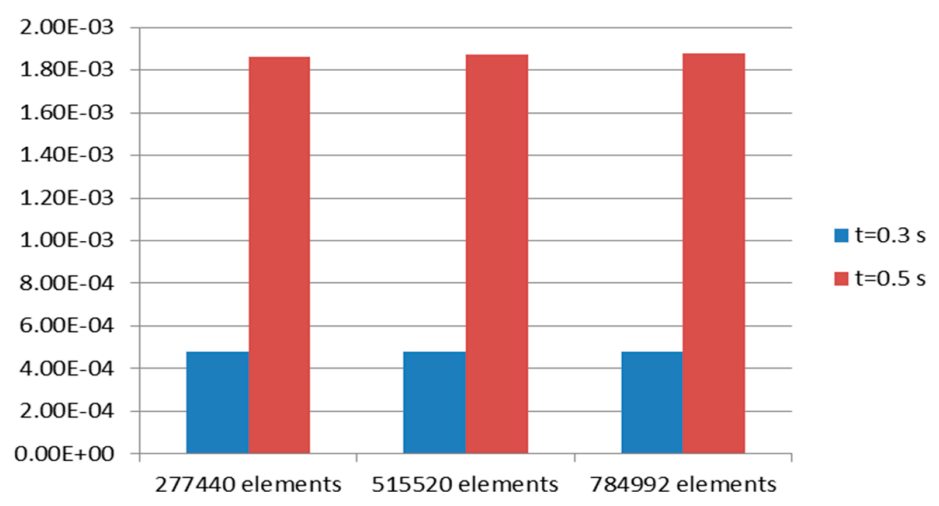

(a)

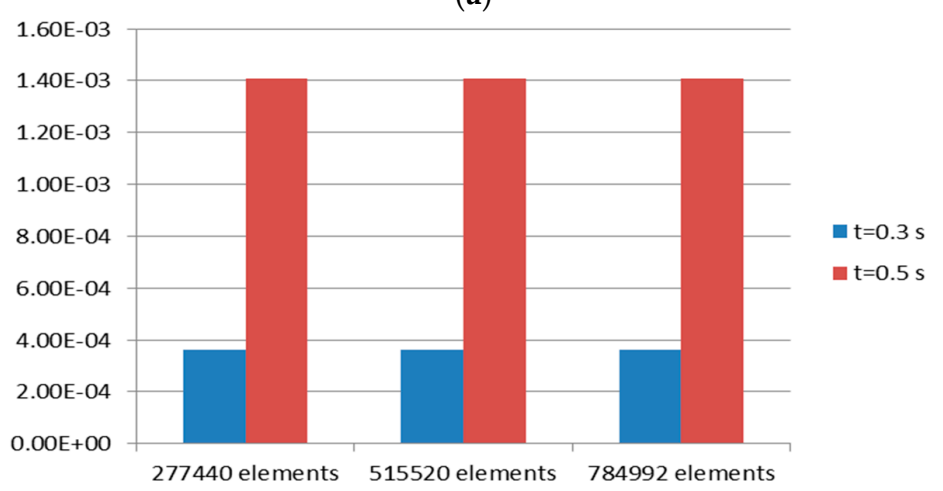

(b)

Figure 6. Mesh convergence test for tissue domain. Von Mises strain at two time values, $t$, was taken as criteria. (a) Maximum strain; (b) minimum strain.

Table 2. Difference of maximum Von Mises strain between solution of Case 3 and two other cases $(t$ is time value).

\begin{tabular}{cccc}
\hline Case Name & Number of Elements & $\boldsymbol{t}=\mathbf{0 . 3} \mathbf{~ s}$ & $\boldsymbol{t}=\mathbf{0 . 5} \mathbf{~ s}$ \\
\hline Case 1 & 277,440 & $3.45 \times 10^{-0.06}$ & $1.40 \times 10^{-0.05}$ \\
Case 2 & 515,520 & $1.24 \times 10^{-0.06}$ & $5.00 \times 10^{-0.06}$ \\
Case 3 & 784,992 & & \\
\hline
\end{tabular}


Table 3. Difference of maximum Von Mises strain between solution of Case 3 and two other cases ( $t$ is time value).

\begin{tabular}{cccc}
\hline Case Name & Number of Elements & $\boldsymbol{t}=\mathbf{0 . 3} \mathbf{~ s}$ & $\boldsymbol{t}=\mathbf{0 . 5} \mathbf{~ s}$ \\
\hline Case 1 & 277,440 & $-1.00 \times 10^{-0.08}$ & $-1.00 \times 10^{-0.07}$ \\
Case 2 & 515,520 & 0.00 & 0.00 \\
Case 3 & 784,992 & & \\
\hline
\end{tabular}

\subsubsection{Airway Strains}

Figure 7 shows maximum Von Mises strain over the domain representing each bifurcation generation. Generally, the highest equivalent strain occurred in Section 3, compared to other sections of bifurcation. The highest equivalent strain is $0.711 \%$ and occurred in Layer 2 (smooth muscle) of Section 3 (mucosa). The maximum equivalent strain distribution from Section 3 also showed a significant difference (up to $0.24 \%$ ) between Layer 1 (cartilage) and 3 (mucosa), compared to the same distribution between Layer 1 and 3 at Sections 1 and 2 (up to $0.015 \%$ and $0.0088 \%$, consecutively).
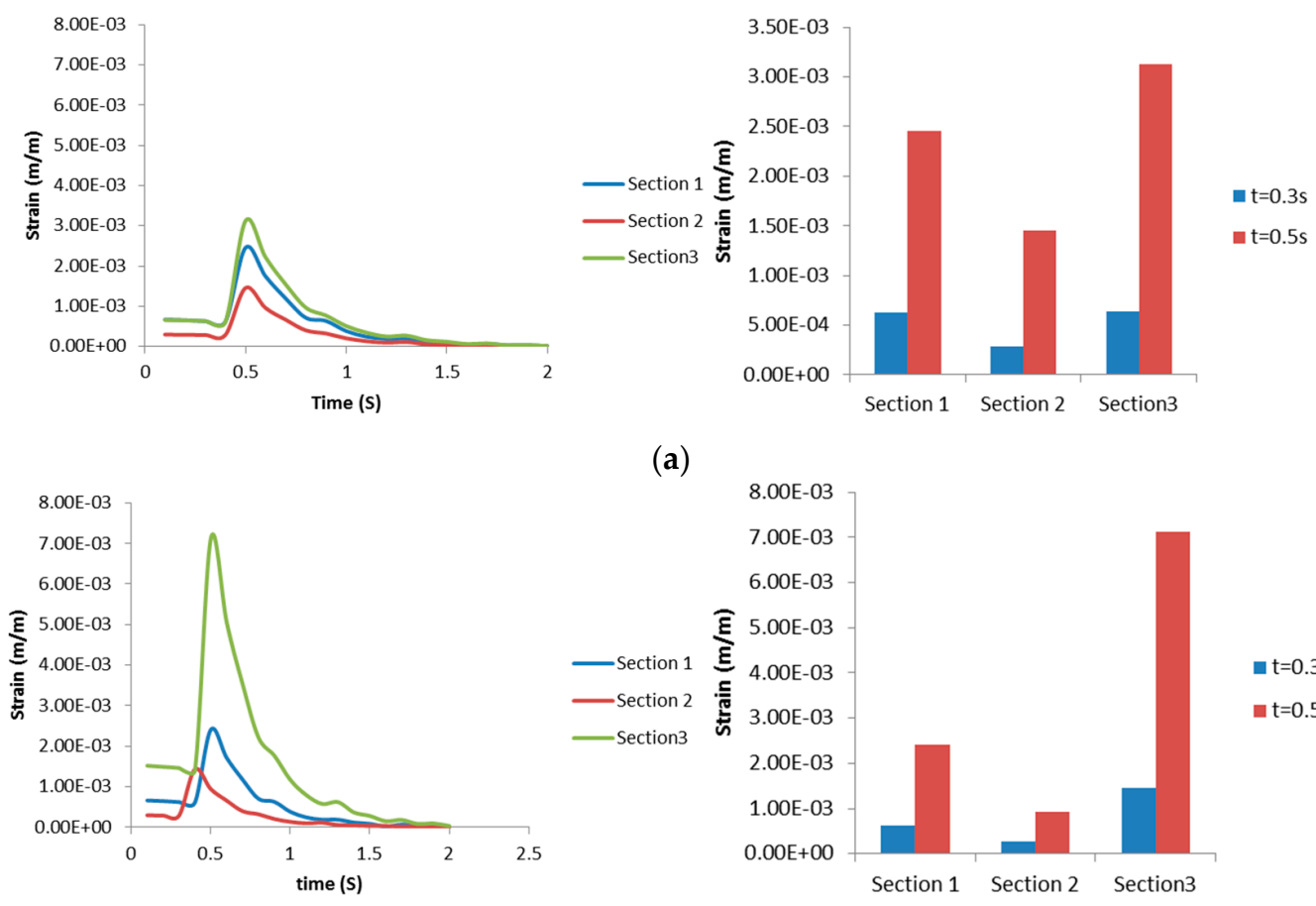

(a)
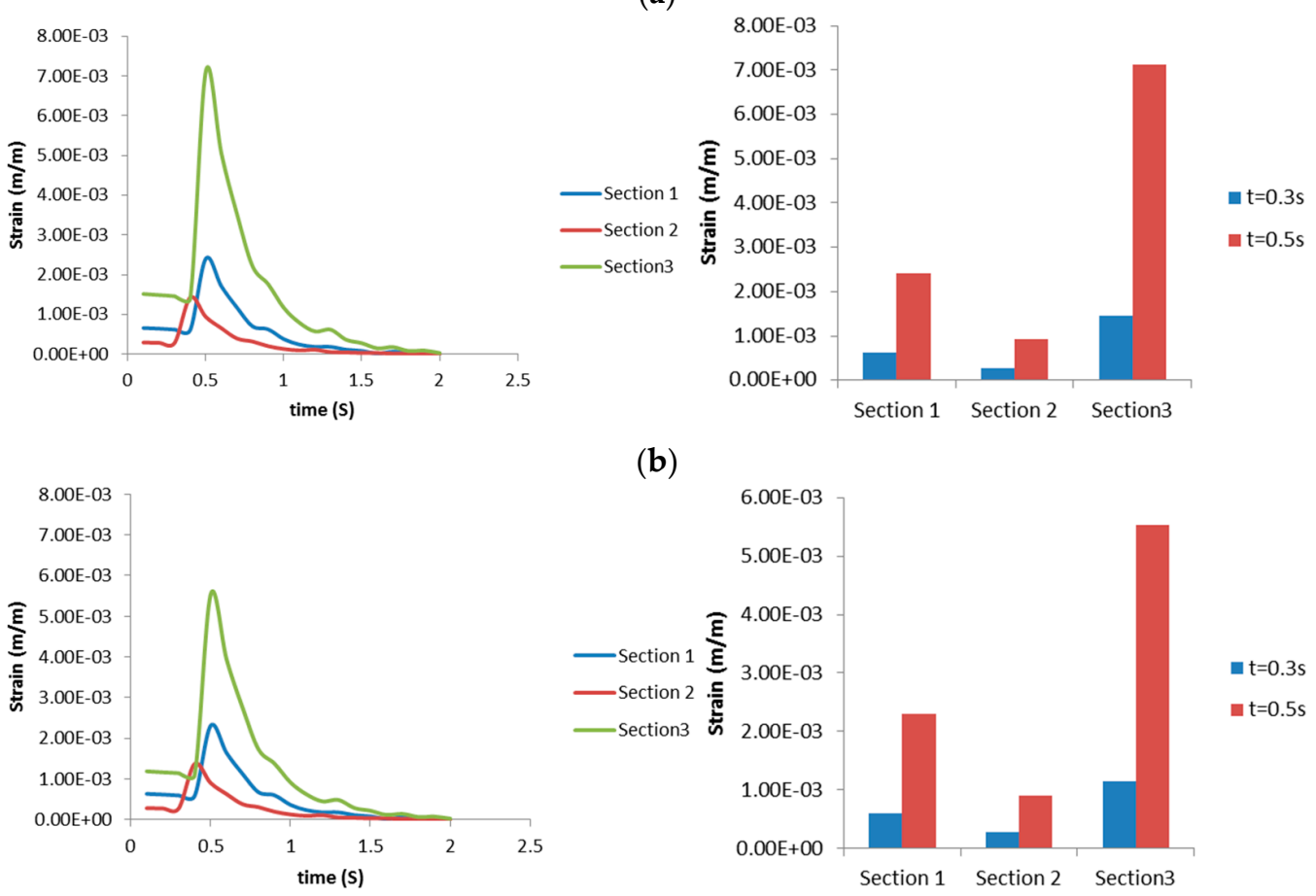

(b)

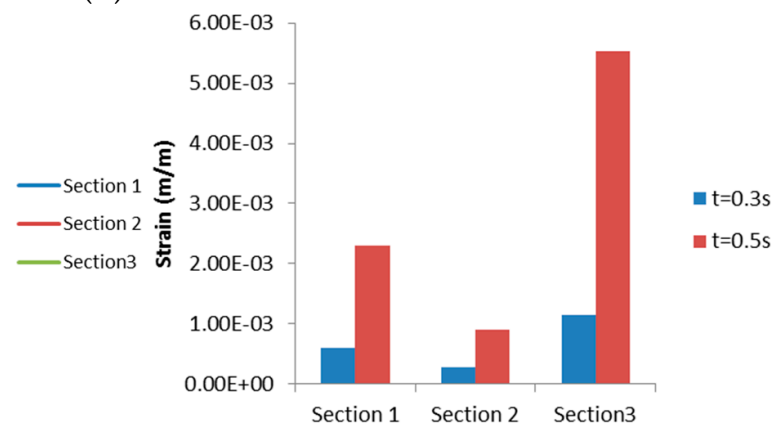

(c)

Figure 7. Maximum Von Mises strains in (a) Layer 1; (b) Layer 2; and (c) Layer 3. Right column shows strain progression over time, left column captures the Von Mises strain at a specific time for a clearer comparison. 

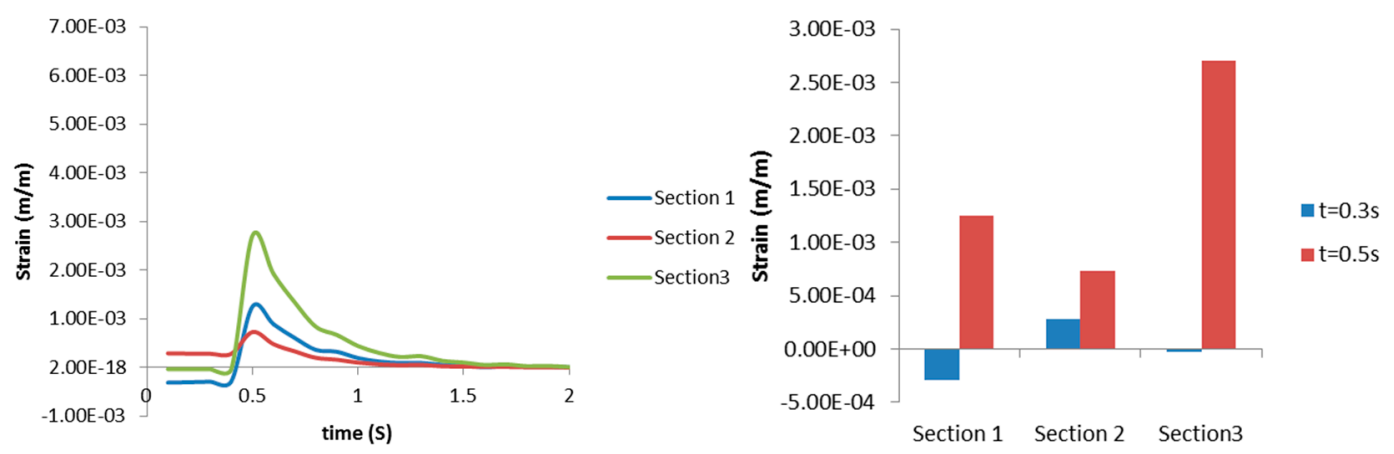

(a)
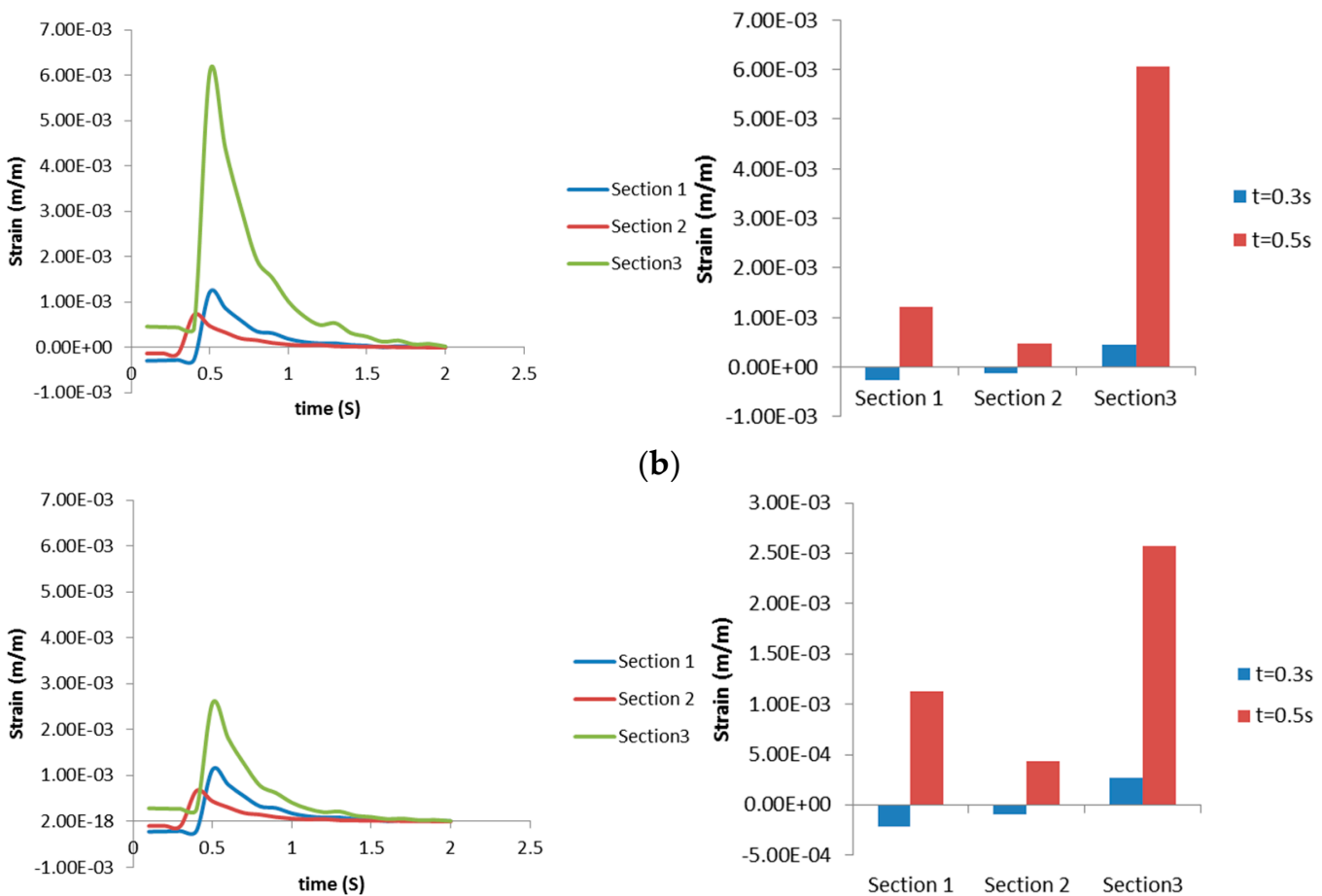

(b)

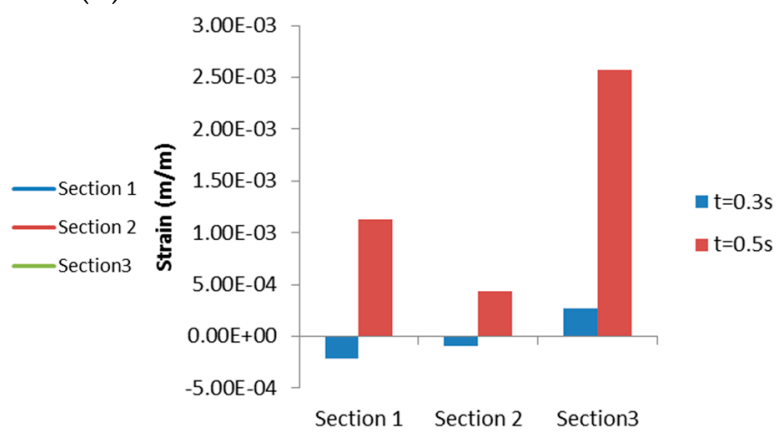

(c)

Figure 8. Maximum radial strains occurring in (a) Layer 1; (b) Layer 2; and (c) Layer 3. Right column shows strain progression over time, left column captures the Von Mises strain at specific time for a clearer comparison.

The maximum radial strains obtained from the structural analysis in each of the sections (Sections 1-3) are shown in Figure 8. It can be seen from Figure 8 that the radial strain is higher in Layer 2 at the location of Section 3. This trend is also true for axial strains (not shown). Also, the direction of radial strain can be different for each layer at the same time, revealing unusual dynamics between layers. Figure 9 shows there is no significant difference of Von Mises strain distribution between Layers, compared to strain distribution between Sections in Figure 7. In both Figure 10a,b, the maximum radial strains in Sections 1 and 2 during inspiration are in the negative direction. In Figure 10c, it is apparent that the direction of maximum radial strains is positive in Layers 2 (smooth muscle) and 3 (mucosa), while maximum axial strain in Section 3 is always in the positive direction during inspiration and expiration. The results presented in Figures 7-10 illustrate the distribution and magnitude of strains in different layers of the tissue during inspiration and expiration. This is very important as the tissue response depends on the composition of the layers making up the tissue. 

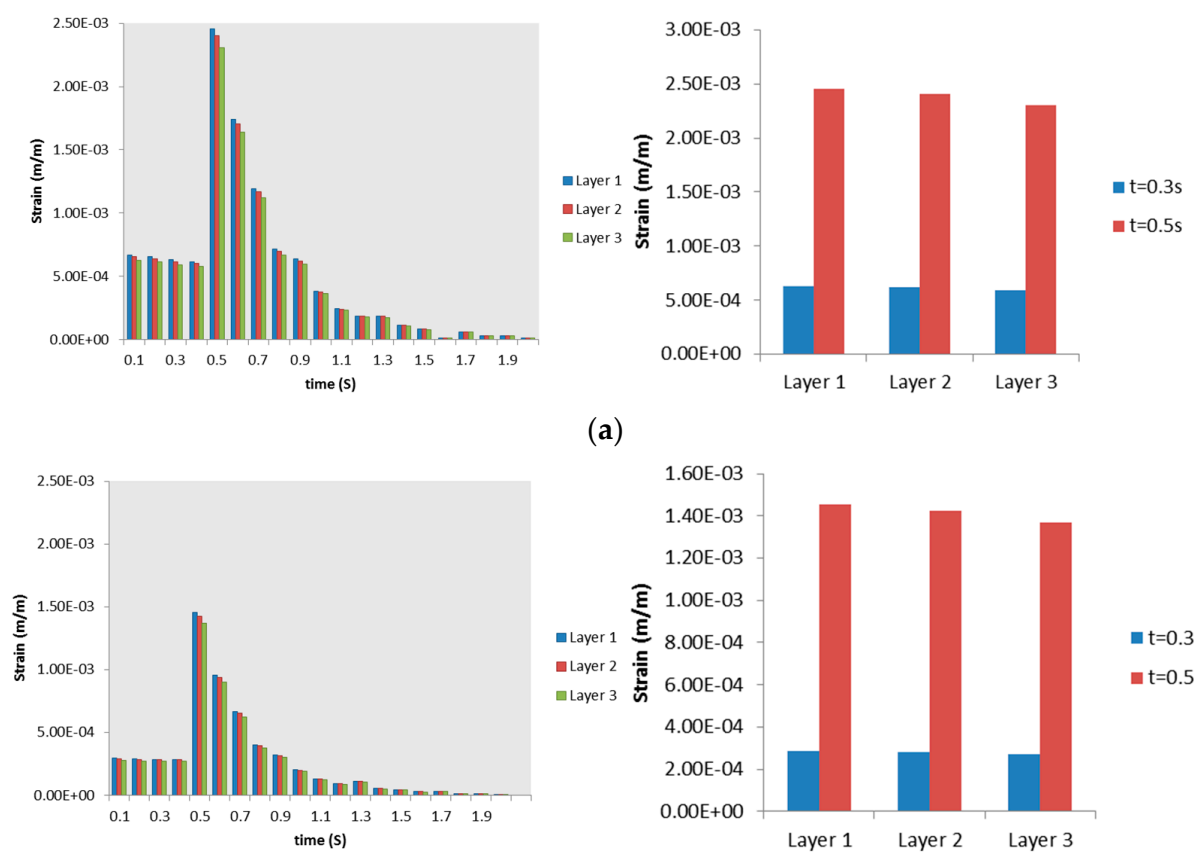

(a)
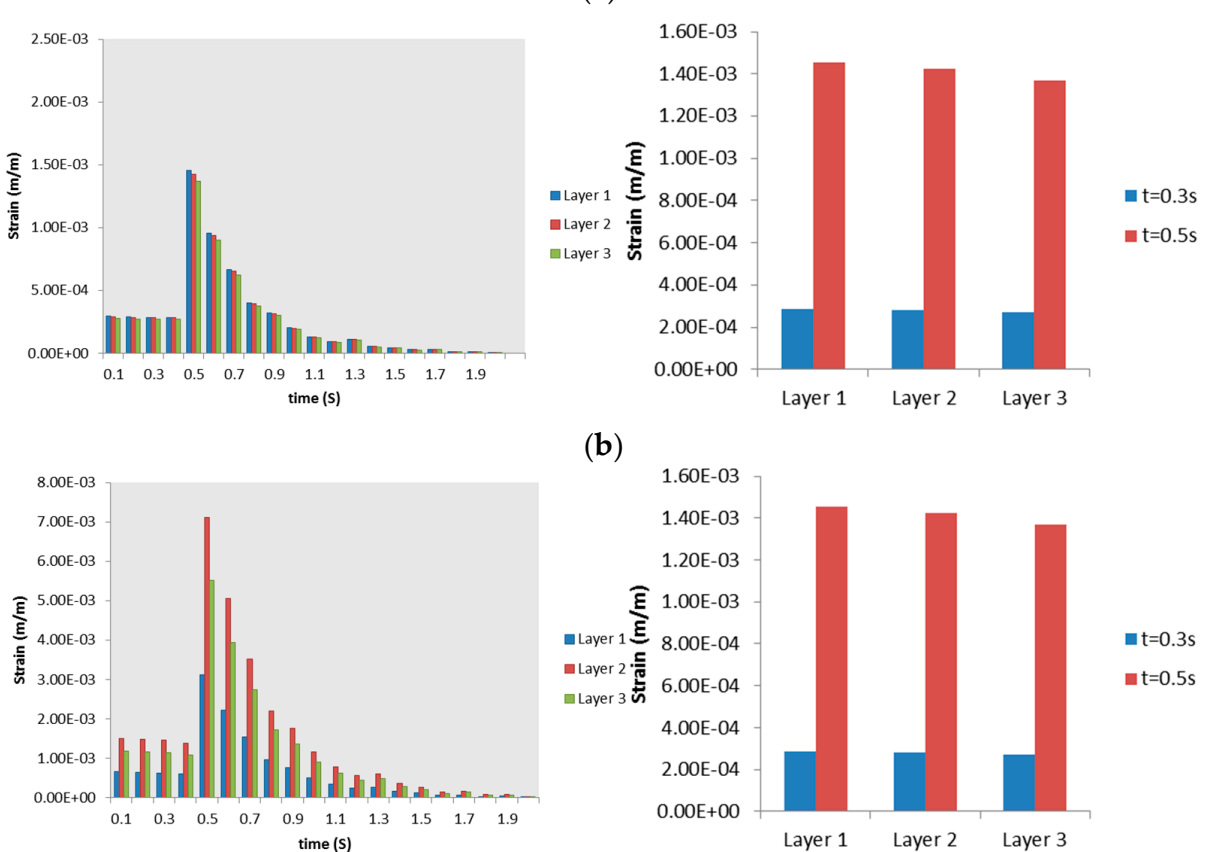

(b)

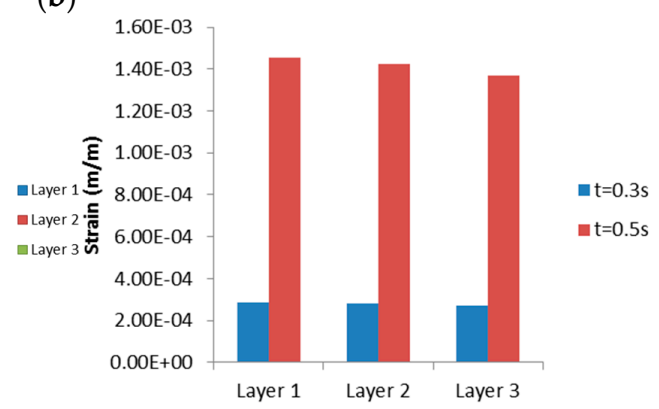

(c)

Figure 9. Maximum Von Mises strains occurring in (a) Section 1; (b) Section 2; and (c) Section 3. Right column shows strain progression over time, left column captures the Von Mises strain at specific time for a clearer comparison.

Figure 11 summarizes strains obtained for each section representing Generation $4-5$ at time $0.5 \mathrm{~s}$. Radial strain dominates over axial strain following our assumption as discussed in Section 2.2.2. It can be clearly seen that von-Mises strain in Section 3 (Generation 5 to the left of bifurcation defined by the illustration) is 2.9 times and 4.89 times the strains in Sections 1 and 2 respectively. The radial and axial components of the strain in Section 3 are also higher than in Section 1 ( 8.15 times for radial and 6.04 times for axial) and Section 2 (4.83 times for radial and 3.6 times for axial).

Figure 12 shows a comparison of strain occurring at Generation 4 (Section 1) at the same time as in Figure $9(t=0.5 \mathrm{~s})$ by using different material models including non-linear, Neo-Hookean and Ogden models. The results were presented in a $\log _{10}$ plot. The Neo-Hookean model produced the smallest range of strains. The von-Mises strain from assuming Neo-Hookean material is $8.16 \times 10^{-4}$ smaller than that obtained from the linear isotropic material relationship. However, the von-Mises strain from applying the Ogden material relationship is 2.48 times higher than a linear isotropic relationship. Since non-linear deformation was ignored in this study, and only basic response (radial and axial strains) was the focus of this study, there was no need to continue using non-linear material relations in this case. However, the Ogden material parameters used in this study may lead to results that better match the linear isotropic ones. 

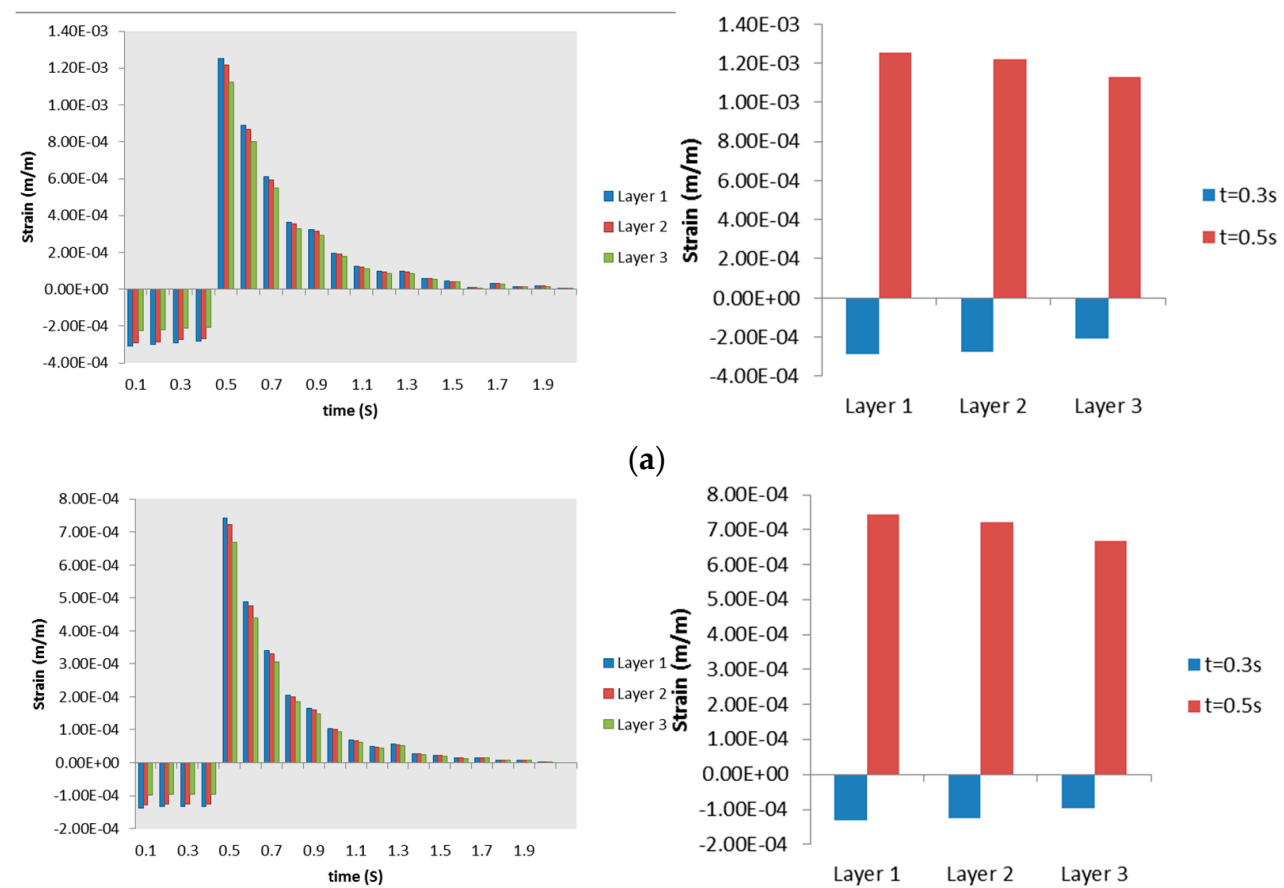

(b)
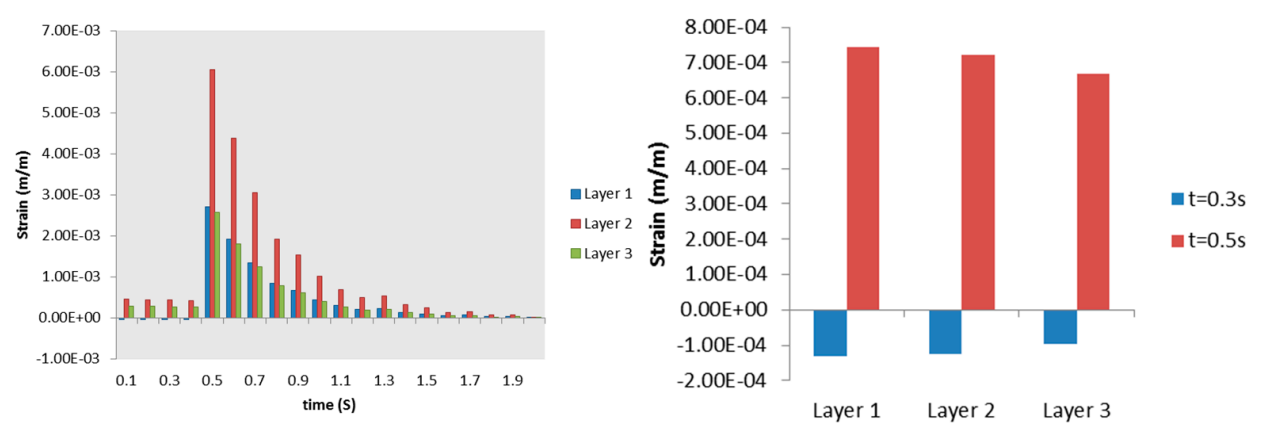

(c)

Figure 10. Maximum radial strains occurring in (a) Section 1; (b) Section 2; and (c) Section 3. Right column shows strain progression over time, left column captures the Von Mises strain at specific time for a clearer comparison.

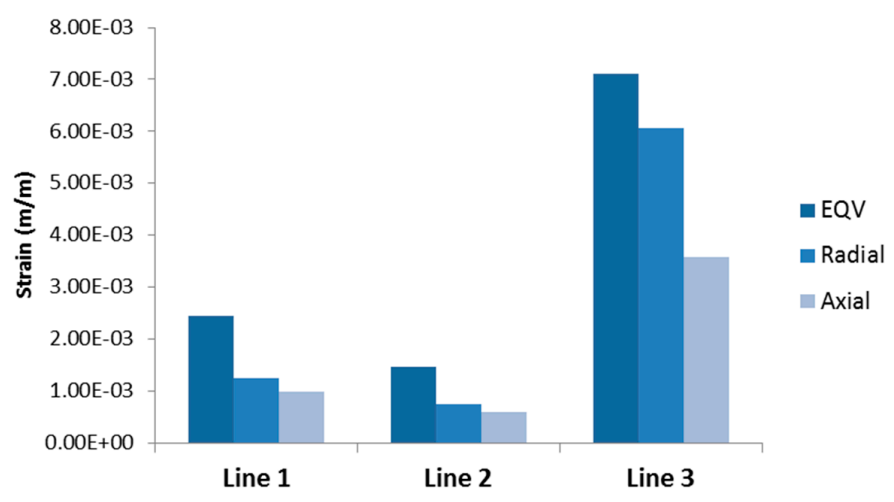

Figure 11. Maximum strains at peak expiration (0.5 s). Von Mises strain in Section 3 is 4.89 times and 2.9 times higher than in Sections 1 and 2 respectively. Radial strain in Section 3 is 8.15 times and 4.83 times higher than in Sections 1 and 2 respectively. Axial strain in Section 3 is 6.04 times and 3.6 times higher than in Sections 1 and 2 respectively. 


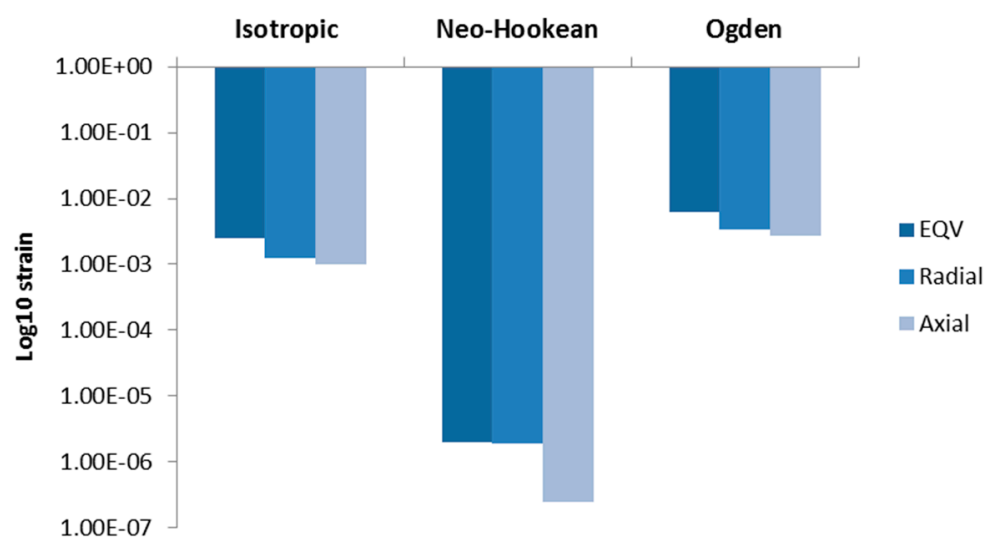

Figure 12. Comparison of maximum strains with different material model at peak expiration $(t=0.5 \mathrm{~s})$. The plot is $\log _{10}$ plot to exaggerate the proportion of strains from Neo-Hookean material model.

\subsection{Discussion}

Figure 3 shows the average transient air pressure at the three locations of the airway. The average air pressure at Sections 2 and 3 (both are Generation 5 of airway) are almost the same, while Section 1 (Generation 4) shows the highest average air pressure distribution during inspiration and expiration. It can be concluded that the air pressure reduces as the air flows through higher generations of airway, as expected. However, this pressure could cause different dynamics at the tissue level that contain three layers. The simplified tissue model used in this study shows that location in one of the Generation 5 (Section 3) bifurcations generates more mechanical response than the location at Generation 4 (Section 1) and Generation 5 (Section 2), as shown in Figures 7 and 8. The Von Mises strain (as mechanical response measure) occurring in one bifurcation of Generation 5 (Section 1) is about four times higher than in another bifurcation of the same generation (but with different bifurcation).

The only physical difference between the two Generation 5 sections here is the radius (and consequently the thickness of each layer); generation in Section $2(1.86 \mathrm{~mm}$ in diameter) is about 0.8 times bigger than in Section 3 ( $1.45 \mathrm{~mm}$ in diameter). When subjected to almost similar pressure cycles, these two sections behaved differently. The mechanical response can be up to four times higher for the bigger bifurcation as described in the previous section. The material properties of the two sections in Generation 5 are the same, and the loadings are similar as shown in Figure 3, however, the thickness is different. This suggests sensitivity to geometrical features. Further study is needed to determine factors that caused different mechanical responses in the same generation in this study.

The importance of investigating strain as a mechanical response lies in its ability to detect/assess inflammation and cell signaling. It is known that cyclic mechanical strain induces varied cell signaling, such as shown in [26]. Mechanical strain may change the properties of the airway [27] and lead to inflammation. The mechanism of inflammation associated with MV breathing is not well established and there are different proposed mechanisms, such as discussed in [28] and [7]. Additionally, some authors have conducted experiments to determine a strain threshold that leads to inflammation $[29,30]$. However, combining mechanical analysis as presented in this study with stochastic modeling of inflammation (such as [31]) may reveal important dynamics between organ level and cell level mechanics that lead to tissue injury and/or differences in airway properties.

\section{Conclusions}

In this study, a multi-level modeling scheme was employed to investigate mechanical responses caused by air pressure during MV breathing. A bifurcation at Generation 4-6 of a realistic human lung model was considered for this study. ANSYS software package v.14 was used to solve equations for modeling airflow and structural responses of the airway. One section in Generation 4 and two sections 
in Generation 5 were selected for structural analysis. Fluid flow simulation showed expected pressure distribution from higher generations to lower ones. Mechanical responses to the air pressure in three locations of bifurcation showed different dynamics between two sections at the same generation with similar transient load. Mechanical response at the same generation but with different bifurcation can differ by up to eight times (peak radial strain in Section 3 is eight times that of Section 2). This result suggests sensitivity to geometrical features. Further study is needed to quantify the sensitivity of mechanical responses to geometrical features.

Acknowledgments: The authors thank the NSF for support this research through a grant CMMI-1430379.

Author Contributions: Aghasafari conducted airflow simulation study and post-processing of the results. Bin M. Ibrahim conducted mechanical response analysis, post-processed the results and wrote the paper. Pidaparti designed the study and contributed to the writing of the paper.

Conflicts of Interest: The authors declare no conflict of interest.

\section{References}

1. Ricard, J.D.; Dreyfuss, D.; Saumon, G. Ventilator-induced lung injury. Eur. Respir. J. Suppl. 2003, 42, S2-S9. [CrossRef]

2. Pinhu, L.; Whitehead, T.; Evans, T.; Griffiths, M. Ventilator-associated lung injury. Lancet 2003, 3613, 32-40. [CrossRef]

3. Parker, J.C.; Townsley, M.I.; Rippe, B.; Taylor, A.E.; Thigpen, J. Increased microvascular permeability in dog lungs due to high peak airway pressures. J. Appl. Physiol. 1984, 571, 1809-1816.

4. Dreyfuss, D.; Saumon, G. Role of tidal volume, FRC, and end-inspiratory volume in the development of pulmonary edema following mechanical ventilation. Am. Rev. Respir. Dis. 1993, 1481, 1194-1203. [CrossRef] [PubMed]

5. Hernandez, L.A.; Peevy, K.J.; Moise, A.A.; Parker, J.C. Chest wall restriction limits high airway pressure-induced lung injury in young rabbits. J. Appl. Physiol. 1989, 662, 2364-2368.

6. Dos Santos, C.C.; Slutsky, A.S. The contribution of biophysical lung injury to the development of biotrauma. Annu. Rev. Physiol. 2006, 68, 585-618. [CrossRef] [PubMed]

7. Ning, Q.; Wang, X. Activations of mitogen-activated protein kinase and nuclear factor-kappaB by mechanical stretch result in ventilation-induced lung injury. Med. Hypotheses 2007, 683, 56-60. [CrossRef]

8. Matsuoka, T.; Kawano, T.; Miyasaka, K. Role of high-frequency ventilation in surfactant-depleted lung injury as measured by granulocytes. J. Appl. Physiol. 1994, 765, 539-544.

9. Sugiura, M.; McCulloch, P.R.; Wren, S.; Dawson, R.H.; Froese, A.B. Ventilator pattern influences neutrophil influx and activation in atelectasis-prone rabbit lung. J. Appl. Physiol. 1994, 771, 1355-1365.

10. Guan, X.; Segal, R.A.; Shearer, M.; Martonen, T.B. Mathematical Model of Airflow in the Lungs of Children II: Effects of Ventilatory Parameters. J. Theor. Med. 2000, 3, 51-62. [CrossRef]

11. Kleinstreuer, C.; Zhang, Z. Targeted drug aerosol deposition analysis for a four-generation lung airway model with hemispherical tumors. J. Biomech. Eng. 2003, 125, 197-206. [CrossRef] [PubMed]

12. Yang, X.L.; Liu, Y.; Luo, H.Y. Respiratory flow in obstructed airways. J. Biomech. 2006, 39, 2743-2751. [CrossRef] [PubMed]

13. Brouns, M.; Jayaraju, S.T.; Lacor, C.; de Mey, J.; Noppen, M.; Vincken, W.; Verbanck, S. Tracheal stenosis: A flow dynamics study. J. Appl. Physiol. 2007, 102, 1178-1184. [CrossRef] [PubMed]

14. Koombua, K.; Pidaparti, R.M. Inhalation Induced Stresses and Flow Characteristics in Human Airways through Fluid-Structure Interaction Analysis. Model. Simul. Eng. 2008. Available online: http://www. hindawi.com/journals/mse/2008/358748/ (accessed on 28 September 2015). [CrossRef]

15. Rolle, T.; Pidaparti, R.M. Tissue strains induced in airways due to mechanical ventilation. In Proceedings of the ASME Early Career Technical Conference, Atlanta, Georgia, USA, 4-5 November 2011.

16. Pidaparti, R.M.; Koombua, K. Tissue strains induced in airways due to mechanical ventilation. Mol. Cell Biomech. 2011, 81, 149-168.

17. Koombua, K.; Pidaparti, R.M.; Longest, P.W.; Ward, K.R. Biomechanical Aspects of Compliant Airways due to Mechanical Ventilation. Mol. Cell Biomech. 2009, 6, 203-216. [PubMed]

18. Kamm, R.D. Airway wall mechanics. Annu. Rev. Biomed. Eng. 1999, 1, 47-72. [CrossRef] [PubMed] 
19. Bai, A.; Eidelman, D.H.; Hogg, J.C.; James, A.L.; Lambert, R.K.; Ludwig, M.S.; Martin, J.; McDonald, D.M.; Mitzner, W.A.; et al. Proposed nomenclature for quantifying subdivisions of the bronchial wall. J. Appl. Physiol. 1994, 72, 1011-1014.

20. Arambakam, R.; Pidaparti, R.; Reynolds, R.M.; Heise, A. Computational Fluid Dynamics Anslysis of Typical Lower Lung Bifurcations under Mechanical Ventilation and Normal Breathing. In Proceedings of the Fourteenth Annual Early Career Technical Conference, Birmingham, UK, 1-2 November 2014.

21. Weed, B.; Patnaik, S.; Rougeau-Browning, M.; Brazile, B.; Liao, J.; Prabhu, R.; Williams, L. Experimental Evidence of Mechanical Isotropy in Porcine Lung Parenchyma. Materials 2015, 82, 2454-2466. [CrossRef]

22. Xia, G.; Tawhai, M.H.; Hoffman, E.A.; Lin, C.L. Airway wall stiffening increases peak wall shear stress: A fluid-structure interaction study in rigid and compliant airways. Ann. Biomed. Eng. 2010, 38, 1836-1853. [CrossRef] [PubMed]

23. Zeng, Y.J.; Yager, D.; Fung, Y.C. Measurement of the Mechanical Properties of the Human Lung Tissue. J. Biomech. Eng. 1987, 109, 169-174. [CrossRef] [PubMed]

24. Sul, B.; Wallqvist, A.; Morris, M.J.; Reifman, J.; Rakesh, V. A computational study of the respiratory airflow characteristics in normal and obstructed human airways. Comput. Biol. Med. 2014, 52, 130-143. [CrossRef] [PubMed]

25. Isabey, D.; Chang, H.K. A model study of flow dynamics in human central airways. Part II: Secondary flow velocities. Respir. Physiol. 1982, 499, 97-113. [CrossRef]

26. Shah, M.R.; Wedgwood, S.; Czech, L.; Kim, G.A.; Lakshminrusimha, S.; Schumacker, P.T.; Steinhorn, R.H.; Farrow, K.N. Cyclic stretch induces inducible nitric oxide synthase and soluble guanylate cyclase in pulmonary artery smooth muscle cells. Int. J. Mol. Sci. 2013, 144, 4334-4348. [CrossRef] [PubMed]

27. Tepper, R.S.; Ramchandani, R.; Argay, E.; Zhang, L.; Xue, Z.; Liu, Y.; Gunst, S.J. Chronic strain alters the passive and contractile properties of rabbit airways. J. Appl. Physiol. 2005, 98, 1949-1954. [CrossRef] [PubMed]

28. Chapman, K.E.; Sinclair, S.E.; Zhuang, D.; Hassid, A.; Desai, L.P.; Waters, C.M. Cyclic mechanical strain increases reactive oxygen species production in pulmonary epithelial cells. Am. J. Physiol. Lung Cell Mol. Physiol. 2005, 289, L834-L841. [CrossRef] [PubMed]

29. Chandel, N.S.; Sznajder, J.I. Stretching the lung and programmed cell death. Am. J. Physiol. Lung Cell Mol. Physiol. 2000, 279, L1003-L1004. Available online: http://ajplung.physiology.org/content/279/6/ L1003.abstract (accessed on 15 March 2015).

30. Copland, I.B.; Post, M. Stretch-activated signaling pathways responsible for early response gene expression in fetal lung epithelial cells. J. Cell. Physiol. 2007, 210, 133-143. [CrossRef] [PubMed]

31. Reynolds, A.; Koombua, K.; Pidaparti, R.M.; Ward, K.R. Cellular Automata Modeling of Pulmonary Inflammation. Mol. Cell Biomech. 2012, 91, 141-156. [CrossRef]

(C) 2016 by the authors; licensee MDPI, Basel, Switzerland. This article is an open access article distributed under the terms and conditions of the Creative Commons by Attribution (CC-BY) license (http://creativecommons.org/licenses/by/4.0/). 